\title{
Revisiting simple methods to estimate drop size distributions: a novel approach based on infrared thermography
}

\author{
João L.M.P. de Lima ${ }^{1,2 *}$, Valdemir P. Silva Jr. ${ }^{3}$, M. Isabel P. de Lima ${ }^{1,2}$, João R.C.B. Abrantes ${ }^{1,2}$, \\ Abelardo A.A. Montenegro ${ }^{3}$
}

${ }^{1}$ Department of Civil Engineering, Faculty of Science and Technology of the University of Coimbra (FCTUC), Rua Luís Reis Santos, Campus II - University of Coimbra, 3030-788 Coimbra, Portugal.

${ }^{2}$ Institute of Marine Research (IMAR) and Marine and Environmental Sciences Centre (MARE), Department of Life Sciences, University of Coimbra, 3004-517 Coimbra, Portugal.

${ }^{3}$ Rural Federal University of Pernambuco, Department of Agricultural Engineering, Rua Dom Manoel de Medeiros s/n, Dois Irmãos, CEP 50910-130 Recife, PE, Brazil.

*Corresponding author. Tel.: +351 239797183. E-mail: plima@dec.uc.pt

\begin{abstract}
The infrared thermography has been successfully applied as a tool for high resolution imaging in different hydrological studies. This exploratory experimental study aimed at evaluating the possibility of using infrared thermography to determine the diameter of raindrops. Rain samples are collected on a pre-heated acrylic board, which is exposed to rain during an instant, and thermograms are recorded. The area of the thermal stains ("signatures" of the raindrops) emerging on the board is measured and converted to drop diameters, applying a calibration equation. Diameters of natural raindrops estimated using this technique were compared with laser disdrometer measurements; the Nash-Sutcliffe efficiency coefficient was used for evaluating the match between the resulting histograms of drop size distribution. Results confirm the usefulness of this simple technique for sizing and counting raindrops, although it is unsatisfactory in light rain or drizzle.
\end{abstract}

Keywords: Rainfall; Thermography; Drop size distributions; Drop diameters.

\section{INTRODUCTION}

Precipitation is the key hydrological variable linking the atmosphere to land surface processes while playing a dominant role in many of these processes. It occurs in a variety of forms: precipitation may fall as rain, sleet, snow, hail or freezing rain, depending on the conditions in the atmosphere at that moment in time. In the form of rain it consists of liquid water falling to the Earth's surface as individual raindrops, which occur in varying numbers, sizes and fall speeds, and having different landing positions.

In hydrology, and also in meteorology, many studies of rain have typically concentrated on its average properties over sufficiently large volumes and time intervals, and not on characterizing the exact positions, sizes and fall speeds of the individual raindrops. In such case, the stochastic and discrete nature of rainfall at smaller spatial and temporal scales is usually treated only in a statistical sense. The small scale variability of rainfall is represented by means of the statistical distributions of the number, position, size and fall speed of the raindrops within a reference volume or time interval (e.g. Cataneo and Stout, 1968; Hauser et al., 1984; Jones, 1992; Wang and Pruppacher, 1977). However, there is scarce information on these properties because of technical limitations of measuring methods, among other reasons. It also happens that the spatial and temporal scales associated with the microstructure of rainfall are often thought to be insignificant as compared to the characteristic scales of typical hydrological processes such as rainfall-runoff transformations. Nevertheless, some relatively recent developments have contributed to the increased interest of the hydrological community in the microstructure of rainfall; we identify, for example, the use of weather radars for estimating the spatial and temporal distribution of rainfall (e.g. Atlas et al., 1973; Sekhon and Srivastava, 1971; Uijlenhoet, 1999) and the attention devot- ed to understanding processes at the land surface, such as soil detachment and erosion by raindrop impact, infiltration of rain water into the soil, surface runoff and interception by vegetation canopies. In general, these are highly nonlinear processes to which every raindrop can make a significant contribution.

There have been also some developments in relation to assessing raindrop properties. In particular, rainfall drop size distributions and mean drop size can be determined using various methods and equipments. There exist two types of instruments to estimate the raindrop size distribution, namely volume integrating devices and time integrating devices. Examples of devices (and examples of early studies) that provide instantaneous measurements of the number and size of raindrops present in a particular sample volume are the raindrop camera (e.g. Cataneo and Stout, 1968; Jones, 1992) and the optical array probe (e.g. Knollenberg, 1970). The vertically pointing Doppler radars can also be included in this class (e.g. Atlas et al., 1973; Sekhon and Srivastava, 1971), although this technology lacks the ability to resolve individual raindrops (e.g. Uijlenhoet, 1999). Time integrating devices provide indirect estimates of the number and size of raindrops arriving at a surface (generally at or near the ground level) during a particular sample interval. Earlier proposed techniques carried out such measurements using, for example, the flour method (e.g. Bentley, 1904; Laws and Parsons, 1943), the blotter paper stain method (or filter paper method; e.g. Jarman, 1956; Magarvey, 1957; Marshall et al., 1947) or the oil method (e.g. Eigel and Moore, 1983). With the paper blotter stains method raindrop size is computed from the size of the permanent rough circular stains that emerge on treated paper when it is wetted by raindrops. The oil method has the advantage of being a direct measurement technique that requires no calibration and no special equipment except a camera, and has been reported to be easy to use both in the laboratory and in the field (e.g. Eigel and Moore, 1983). Another simple 
way to get an approximate idea of the droplets' diameter is to expose to rain a very thin sheet of aluminium foil; the drops will make a dent in the foil that is perhaps $50 \%$ larger than the size of the drop, which can then be measured (e.g. Eigel and Moore, 1983). A similar process is by spreading a thin layer of baking grease on a piece of hard plastic or smooth wood; falling raindrops will make a hole in the grease that is not much larger than the raindrop diameter. These latter measurement techniques will work well for sparse raindrops, not a heavy rain (which will just spread all over the surfaces). Moreover, some of these simple techniques involve quite time consuming data processing; in addition, their accuracy and efficiency are limited because they depend a lot on human measurement. Pearson and Martin (1957) offer a review of early attempts to assess the number, size and fall speed of raindrops, at the edge of technological developments that have changed considerably the approaches used to obtain such data. Thus, more recently, other options for measuring raindrops are, for example, electromechanical disdrometers (e.g. Joss and Waldvogel, 1969) and optical spectrometers (e.g. Bradley and Stow, 1974; Hauser et al., 1984; Wang et al., 1979). While offering the possibility to acquire high resolution data and continuous records, some of the latter techniques use expensive equipment and require the capability to handle and analyse large data sets. The absence of required conditions makes it still necessary to consider the possibility of using simplified methods to get insight into the drop size distribution. However, one seeks simplified methods of a different nature than the ones used in the past, which are typically time consuming and highly dependent on human judgment.

Thus, the main objective of this experimental study is to explore the possibility of using infrared thermography to estimate the mean drop diameter and the drop size distribution of natural rainfall; for this purpose, results are compared with laser disdrometer measurements. Infrared thermography is a technique for non-contact detection of the distribution of thermal energy emitted by radiation by the surface of an object. This technology is able to detect, visualize and record different levels of temperature distribution across the surface of an object, without causing disruption. The use of thermal imaging cameras has been gaining popularity due to their easy handling and lower prices and has opened new areas of use for various hydrological applications. Infrared thermography has already been applied in many hydrological studies (e.g. Cardenas et al., 2008; Danielescu et al., 2009; de Lima and Abrantes, 2014a, b; de Lima et al., 2014; Mejías et al., 2012; Pfister et al., 2010; Schuetz et al., 2012). As far as we know, the innovative application of this technology proposed here is a first attempt for characterizing raindrops' size using thermography. It can be a useful and significant tool in soil erosion's experimental studies that might miss specialized equipment to observe and analyse rain.

\section{MATERIALS AND METHODS Setup}

A schematic representation of the setup used in our experimental work is shown in Figure 1. It consists of two main phases: (I) Calibration phase, based on the study of drops formed by hypodermic needles; and (II) Collection of drops of natural rainfall and measurements using a laser disdrometer. In both cases (I) and (II), the drops were collected on a pre-heated board and a thermal image of the surface of the board was obtained using an image recording system consisting of an infrared thermographic camera, a video camera and a computer (Figure 1-middle).

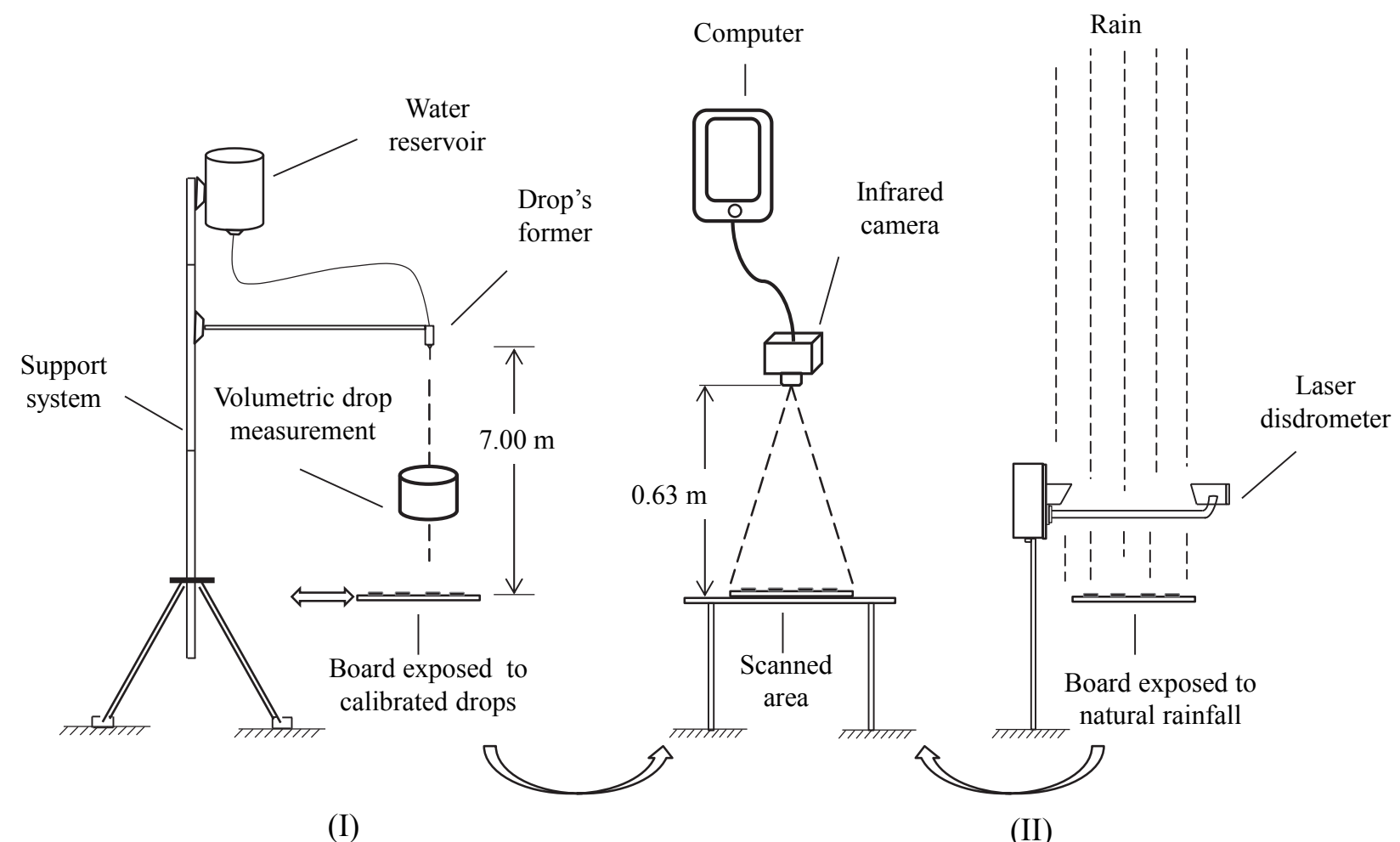

Fig. 1. Scheme of the adopted setup and procedure, including: (I) calibration phase; and (II) sampling of natural rainfall. The image, in the middle, shows the recording system used in both phases (I) and (II). The scheme is not to scale. 


\section{Calibration phase}

For the calibration of the proposed technique (phase I), laboratory experiments were first conducted to study drops of known size and number. Hypodermic needles of different diameters (Figure 1-I) were used to generate drops. The drop former was fed by a constant head reservoir and positioned at a height of $7 \mathrm{~m}$ above the water collection level. Drop fall height of $7 \mathrm{~m}$ is expected to provide drop velocities close to terminal velocity for an expedite sample method. Using needles of diameter $0.8,0.9,1.2$ and $2.0 \mathrm{~mm}$, the system produced drops with mean diameter of $2.74,2.81,3.26$ and $4.90 \mathrm{~mm}$, respectively, at a rate of approximately 1 drop per second. The mean diameter of the formed drops was estimated by collecting one hundred drops on a small container. The collected volume and the assumption of the spherical shape of the drops allowed estimating their size (the average value of 3 repetitions was used).

As part of the calibration phase, drops formed by the hypodermic needles fell on acrylic boards; thermal images (thermograms) of the boards were then recorded using infrared technology. The thermal stains that emerged on the infrared image of the surface of the board, which were caused by the presence of the water (from drops at a temperature lower than the board), were sized. Sizing relied on the thermographic data, as explained below. The estimation of the drops' diameter and the stains' area allowed the development of a calibration equation, to convert stain size into drop size.

The size of the acrylic board used to collect the drops was $300.0 \times 150.0 \times 3.0 \mathrm{~mm}^{3}$. The board was pre-heated to a temperature of $70.0^{\circ} \mathrm{C}$ in a forced ventilation oven and was only removed from the oven immediately before taking samples. Below the drop former, the board was moved slowly while collecting the samples, in order to avoid the accumulation of drops at the same spot. Figure 2 shows photographs of the board after being hit by drops generated by the drop formers.

Immediately after sampling, thermal videos of the boards were recorded with an Optris PI-160 portable infrared video camera (Optris $\mathrm{GmbH}$, Germany) with an optical resolution of $160 \times 120$ pixels, a thermal resolution of $0.1^{\circ} \mathrm{C}$, an accuracy of $\pm 2 \%$, a frame rate of $100 \mathrm{~Hz}$ and a lens with a field of view of $23^{\circ} \times 17^{\circ}$ and focal length of $10 \mathrm{~mm}$. The camera was positioned $0.63 \mathrm{~m}$ above the measuring table (Figure 1-middle). The temperature value corresponding to each pixel represents a thermal stain with an area of $6.5 \mathrm{~mm}^{2}$ of the acrylic plate.

The thermographic data allowed to estimate the size of the thermal stains, as explained below. Very small droplets that result from splatter when drops hit the board are not detected by the technique, due to the resolution of the thermographic cameras. Based on the average values of the thermal stains, recorded using the infrared camera, and the average diameters estimated by the volumetric method, a calibration equation was developed for computing the drop size from the thermal stain size. The validity of the equation is restricted to the range of drop diameters used in its development. This might imply unsatisfactory results for light rain or drizzle.

\section{Sampling natural rainfall}

Samples of natural raindrops were collected in April and June 2014, from frontal rainfall events, just outside the Department of Civil Engineering of the University of Coimbra, Coimbra, in Portugal. The boards used in sampling the rain and the way they were pre-heated were described above. The pre-heated boards remained exposed to natural rain for an instant in order to capture a significant number of drops. After collection of the samples, thermograms were recorded. Their analysis provided estimates of the number and size of the thermal stains. The calibration equation (see above) was then used to compute the drops' size from the stain areas.

Exact sampling time was recorded, for comparison with disdrometer measurements of rain, carried out at the same location. Disdrometer data were used to validate the thermographic technique. Since the distance between the measurements is small, we disregard eventual variations in space of the rainfall characteristics.

The disdrometer data were obtained using a "Laser Precipitation Monitor" (LPM) from Thies Clima (Thies, 2007) (Figure 1-II). This is a laser disdrometer consisting of a laser-optical source that produces a light-beam (detection area is $4777 \mathrm{~mm}^{2}$ ). The instrument determines the size and fall speed of drops by measuring the signal reduction caused by drops falling through the light-beam; the amplitude and duration of the reduced signal is used to estimate the drops' size and fall speed, respectively. The instrument provides information on the total number of drops over 21 size classes (from $0.125 \mathrm{~mm}$ to $8.000 \mathrm{~mm}$ ) and 20 fall speed classes (up to $20.0 \mathrm{~m} \mathrm{~s}^{-1}$ ), each minute.

\section{Thermal imaging analysis}

Infrared thermography, being a technique for non-contact detection of the distribution of thermal energy emitted by radiation by the surface of an object, allows to detect, visualize and record different levels of temperature distribution across the surface of an object, without causing disruption. In the case of our application, we inspect the surface of the rain collector board. The infrared camera yields thermograms, which are graphic records of temperature variations on the surface of the board. They represent radiation in the infrared range of the electromagnetic spectrum, providing identification of pixels associated with different surface temperatures. It is thus possible to identify groups of pixels exhibiting temperature above a given threshold $(\tau)$, which we have called earlier "thermal stains"; they emerge due to the presence of the water on the surface of boards, highlighted by the temperature difference caused by pre-heating the boards prior to wetting. The threshold was assumed equal to the average temperature of the board subtracted by the standard deviation. In this exploratory study, the identification and counting of stains were made manually. The number of pixels in each group gives an estimate of the area of each stain, corresponding to a given drop of a certain size. We use the calibration curve (see Figure 4) to convert stain area into drop diameter.

However, the pre-heated boards undergo a reduction in temperature when exposed to the external environment (e.g. wind, raindrops), which can vary from sample to sample. When sampling natural rainfall, the reduction in the boards' surface temperature is stronger than the reduction in their surface temperature during the calibration phase of the experiments, in the laboratory environment. Thus, it was necessary to correct the temperature records, using the difference between the average temperatures recorded in the boards for the two phases. This correction was carried out individually for each board and collected rain sample, which made it possible to use always the same calibration curve to obtain drop size from thermal stain area. Histograms of the natural rainfall drop size were then obtained for each sample and, consequently, the sample mean drop diameter. 


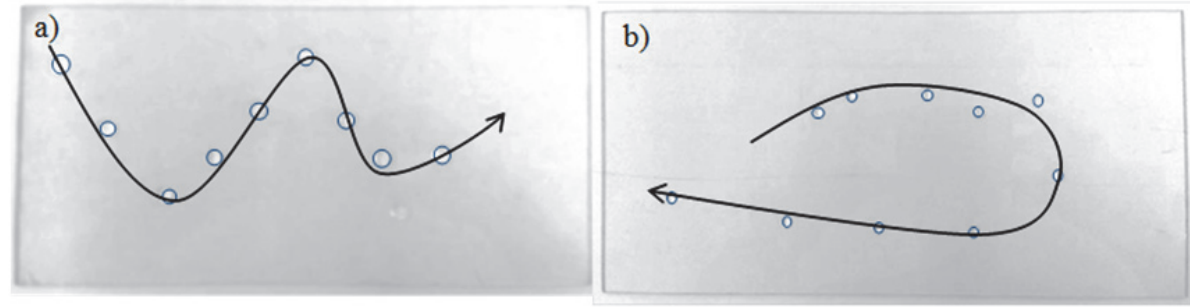

Fig. 2. Photographs of the acrylic boards, after the collection of drops with two diameters, during the calibration phase: a) drops of $4.90 \mathrm{~mm}$ formed by a needle of $2.0 \mathrm{~mm}$, and b) drops of $2.74 \mathrm{~mm}$ formed by a needle of $0.8 \mathrm{~mm}$. Water stains are highlighted with border lines. The curved arrows indicate the approximate motion forced to the board during the collection of drops, to avoid accumulation of drops on the same spot.
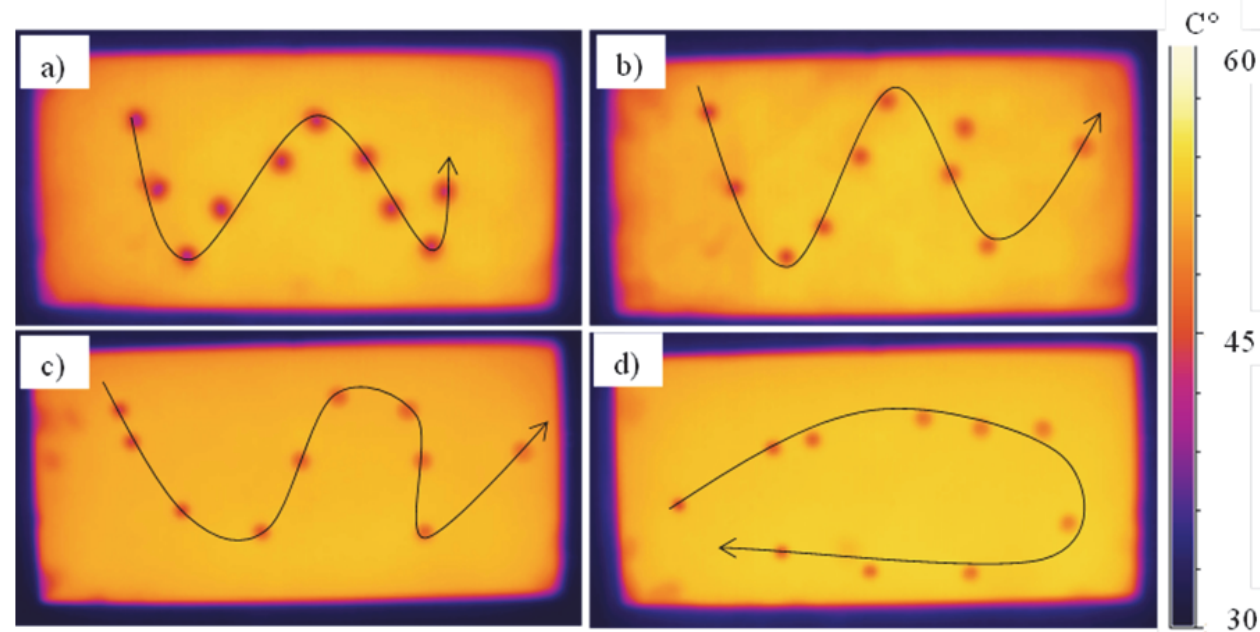

Fig. 3. For the calibration phase, thermograms of the drops' collector board after exposure to drops of 4 sizes, formed by the hypodermic needles, of diameter: a) $4.90 \mathrm{~mm}$; b) $3.26 \mathrm{~mm}$; c) $2.81 \mathrm{~mm}$; and d) $2.74 \mathrm{~mm}$. The curved arrows indicate the approximate motion forced to the board during the collection of drops.

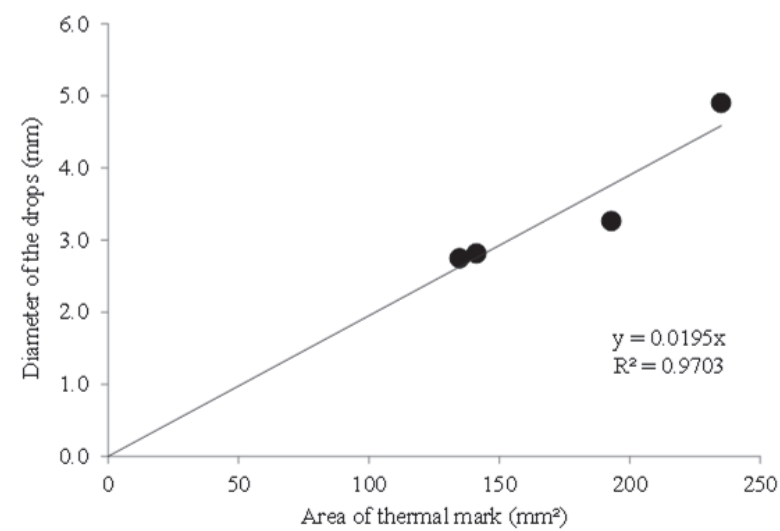

Fig. 4. Area of thermal stains for different raindrop generated by hypodermic needles (diameter estimated by volumetric method). The linear regression line defines a calibration equation, which is used in this study to convert thermal stain area into drop diameter.

\section{Evaluation of thermographic technique}

The proposed technique was evaluated by means of a comparison between the mean diameters and the relative frequency of diameter class intervals obtained with thermography and the disdrometer. The ability of the proposed technique to characterize raindrop sizes, and the relevance of the calibration curve, was assessed using the Nash-Sutcliffe efficiency (NSE) coefficient (e.g. Nash and Sutcliffe, 1970). An efficiency coefficient of $1(\mathrm{NSE}=1)$ corresponds to a perfect fit of the modelled data to the reference data.

\section{RESULTS AND DISCUSSION Calibration phase}

Thermograms of the surface of boards that collected a certain number of equally sized drops formed by hypodermic needles, of 4 different diameters, are shown in Figure 3. Visual observation of the thermograms allows clearly the identification of thermal stains (areas noticeably darker) of different areas, which are created by the presence of water on the surface of the board, for each case; the contrast is because the water temperature is lower than the surface temperature of the board. It is clear that the well defined stains of different sizes, in Figure 3, are proportional to the size of the drops, i.e. bigger drops produce bigger thermal stains.

The number of drops that are detected on the thermal images of the board, as well as their thermal stain area, depends upon the selected threshold temperature $\left(\tau=48.9^{\circ} \mathrm{C}\right.$ in these experiments). Three replicates for each needle drop former used were performed.

Figure 4 shows the assumed linear relation between the known mean diameter of the calibrated drops (estimated by volumetric method) generated by hypodermic needles and the 
correspondent thermal stain area on the drops collector board, which is much larger. Measuring stain sizes is performed by counting pixels of the thermogram. A linear regression line was adjusted to the data $\left(\mathrm{R}^{2}=0.97\right)$. The equation of the fit model is used as a calibration equation to convert the temperature data (i.e. area of the thermal stains) into drop diameters and, thus, to assist obtaining histograms of drop sizes. Note that the limited range of drop sizes studied in this exploratory experiments restricts also the validity of the calibration equation, which can be improved in future applications of this technique.

\section{Analysis of natural raindrops}

Natural raindrops were sampled at different instants during rain storms. Here we discuss the analysis of 9 samples. These samples were collected during two rainfall events: 6 samples were collected during the rain event on April 24, and 3 samples are from the event on May 19, 2014. Figure 5 shows examples of thermograms of the acrylic boards after collection of drops from natural rainfall. Similarly to the thermograms in Figure 3, the thermal stains have different areas, which suggest the signature of drops of different sizes.

Figure 6 shows 3D representations of thermal stains from drop formers (Figures $6 \mathrm{a}$ and $6 \mathrm{~b}$ ) and natural raindrops (Figures $6 \mathrm{c}$ and $6 \mathrm{~d}$ ), emerging on the surface of the collector board. It may be noted that the thermographic technique allows to characterize the spatial distribution of the drops on the surface of the acrylic board. Small raindrops and droplets that are created during impact of the drops on the board are not detected.
The calibration equation in Figure 4 was used to compare the values of the drop diameters obtained by the thermographic technique with the ones recorded by the disdrometer. For each sample, corresponding to a given instant in time, the mean raindrop diameter was determined after converting the thermal stains' area in a given thermogram to drop diameters. The plates were exposed to the rain enough time to collect at least 12 drops.

For the nine samples, these values are represented over time in Figure 7, together with the estimate obtained for the mean drop diameter that correspond to the data collected by the laser disdrometer during the related overlapping minute. Results are similar with respect to the mean drop diameter, for all 9 samples. Table 1 shows the values of the mean diameters estimated from the laser disdrometer records and obtained by the thermographic technique; it also gives the absolute difference between those estimates and the relative errors in the 9 samples. The number of drops identified in each sample is given in Table 1. Sample size is obviously quite different, but we note the good approximation to the 1-minute disdrometer data captured by the "instantaneous" samples analysed with thermography. When comparing mean diameters (disdrometer versus thermographic technique) from the 9 samples, only one estimate had an absolute error higher than $0.1 \mathrm{~mm}$ (average absolute error of $0.07 \mathrm{~mm}$ with a relative error of around $10 \%$ ).

We further attempted to compare the estimates of drop diameters obtained by the thermographic technique and recorded by the disdrometer. For this purpose, the drops' diameters were grouped into classes, and the relative frequency distribution of the size of the raindrops was analyzed. A comparison (disdrometer versus thermography) of the relative frequency calculated
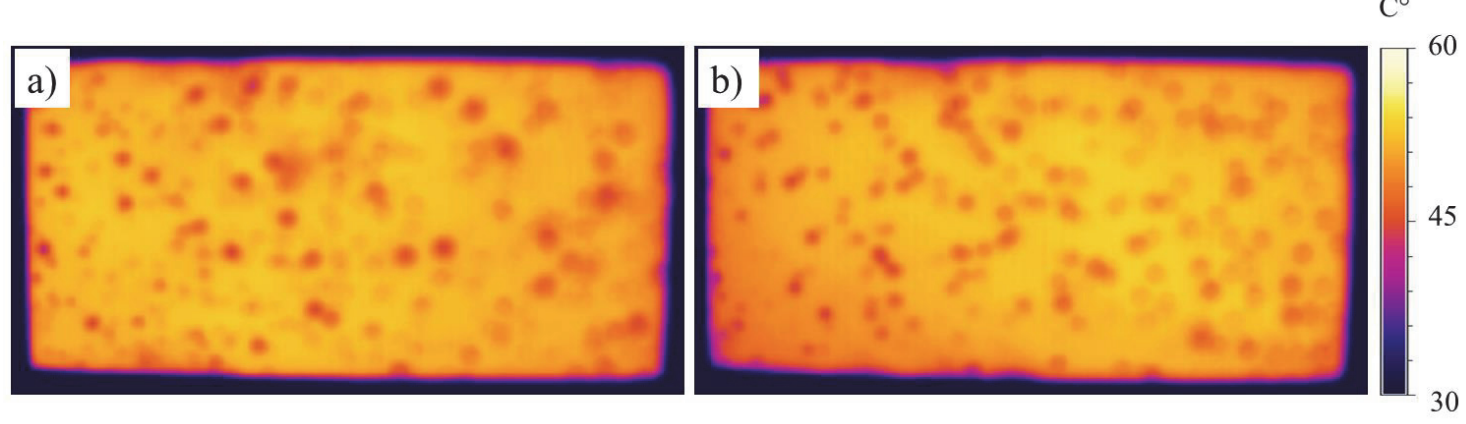

Fig. 5. Examples of thermograms of the surface of the boards after being exposed to natural rainfall for a few seconds.
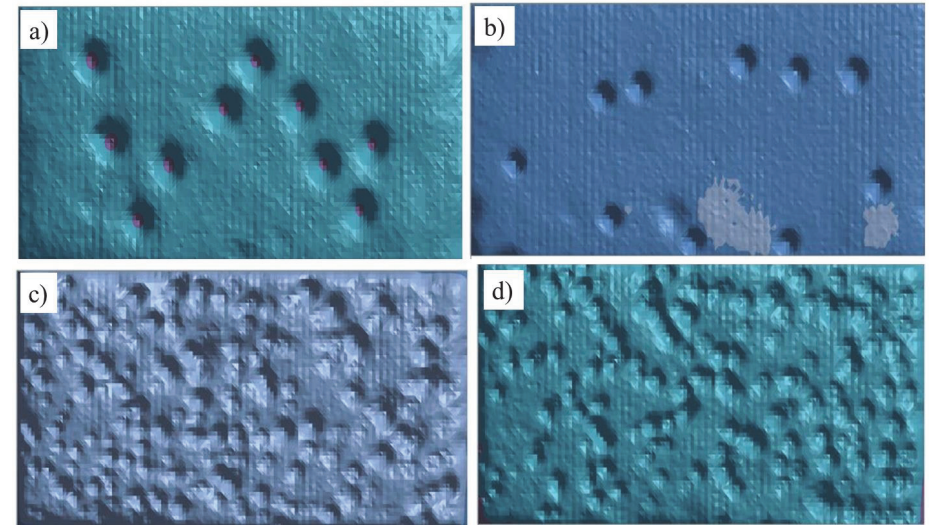

Fig. 6. 3D view of the thermograms of the surface of heated sampling boards showing lower temperature stains: a) and b) created by calibrated drops of 4.90 and $2.74 \mathrm{~mm}$, respectively, formed from needles of 2.0 and $0.8 \mathrm{~mm}$; ) and d) originated by exposition to natural rainfall for a few seconds. 


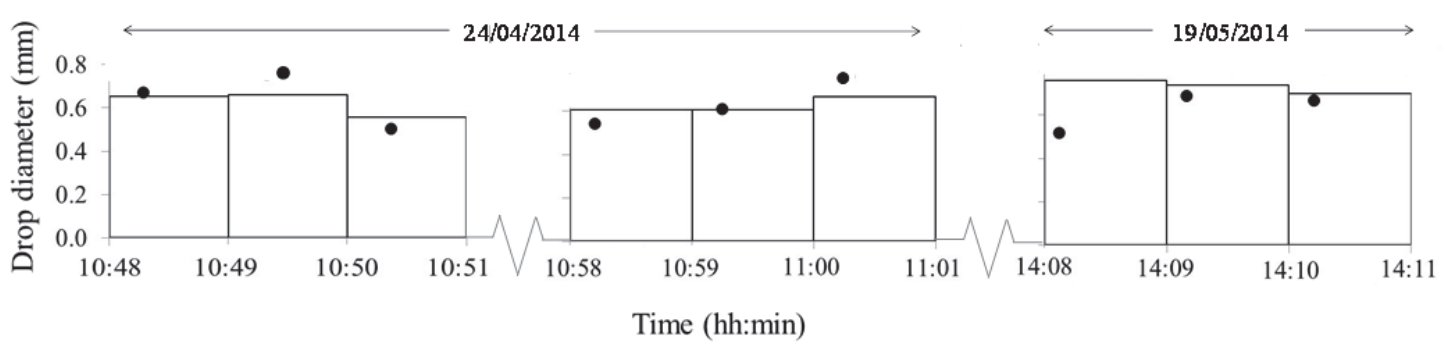

$\square$ Laser distrometer $\bullet$ Thermographic technique

Fig. 7. Mean drop diameters estimated by the thermographic technique (dots), at 9 "instants" in time, and the corresponding laser disdrometer measurements (bars: 1-minute resolution). The data were collected during natural rain events on the 24 April and 19 May, 2014.

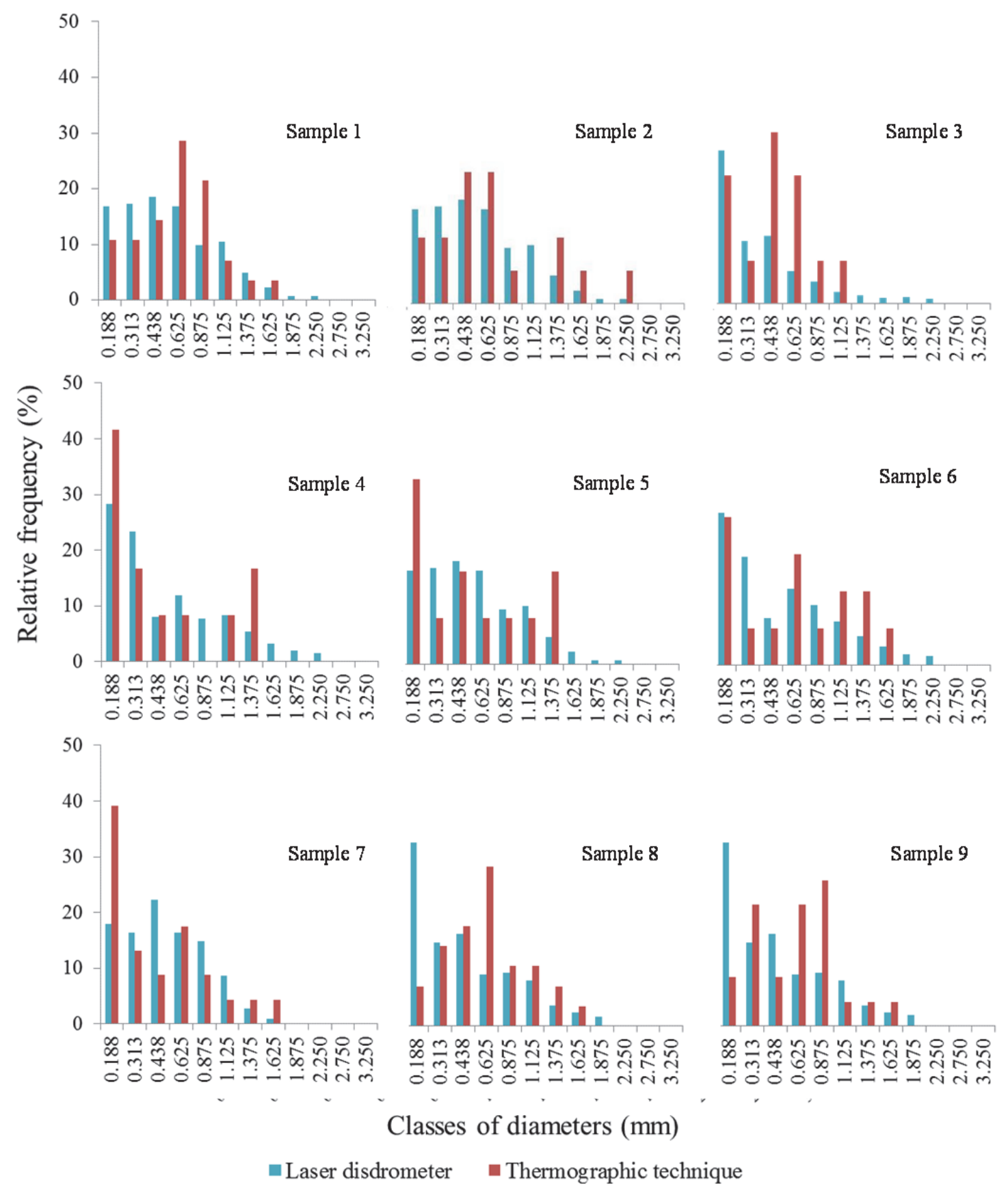

Fig. 8. Comparison of drop diameter empirical histograms for 9 samples of natural rainfall, provided by a laser disdrometer and the thermographic technique. Values on the horizontal axis represent the middle of each diameter class. 
Table 1. Summary of comparative data (disdrometer versus thermographic technique) from 9 samples of natural rain: i) Absolute and relative errors of mean raindrop diameters, and ii) Nash-Sutcliffe coefficient for the relative frequency drop diameter classes of the histogram.

\begin{tabular}{|c|c|c|c|c|c|c|c|}
\hline \multirow[b]{2}{*}{ Samples } & \multicolumn{4}{|c|}{ Mean diameters } & \multicolumn{3}{|c|}{ Histograms } \\
\hline & DD & DT & $|\mathrm{DD}-\mathrm{DT}|$ & |DD-DT|/DD & $\begin{array}{c}\text { *Number of drops } \\
\text { sampled by } \\
\text { thermographic } \\
\text { technique }\end{array}$ & $\begin{array}{l}* * \text { Number of } \\
\text { drops sampled } \\
\text { by disdrometer }\end{array}$ & $\begin{array}{l}\text { Nash-Sutcliffe } \\
\text { coefficient applied to } \\
\text { relative frequency }\end{array}$ \\
\hline & $(\mathrm{mm})$ & $(\mathrm{mm})$ & $(\mathrm{mm})$ & $(\%)$ & $(-)$ & $(-)$ & $(-)$ \\
\hline 1 & 0.65 & 0.67 & 0.02 & 2.6 & 28 & 3267 & 0.61 \\
\hline 2 & 0.66 & 0.75 & 0.09 & 13.7 & 17 & 2085 & 0.66 \\
\hline 3 & 0.56 & 0.50 & 0.06 & 10.2 & 15 & 903 & 0.17 \\
\hline 4 & 0.60 & 0.54 & 0.06 & 10.4 & 14 & 2155 & 0.63 \\
\hline 5 & 0.61 & 0.61 & 0.00 & 0.3 & 13 & 2397 & 0.39 \\
\hline 6 & 0.67 & 0.76 & 0.09 & 14.0 & 15 & 2001 & 0.70 \\
\hline 7 & 0.76 & 0.52 & 0.24 & 31.9 & 23 & 702 & 0.37 \\
\hline 8 & 0.74 & 0.69 & 0.05 & 7.3 & 28 & 857 & 0.20 \\
\hline 9 & 0.70 & 0.67 & 0.03 & 4.7 & 23 & 902 & 0.14 \\
\hline Average & 0.66 & 0.63 & 0.07 & 10.6 & 19.6 & 1697 & 0.43 \\
\hline $\begin{array}{l}\text { Standard } \\
\text { deviation }\end{array}$ & 0.05 & 0.08 & 0.05 & 6.2 & 5.2 & 760.5 & 0.20 \\
\hline $\begin{array}{l}\text { Combined } \\
\text { sample }\end{array}$ & 0.66 & 0.63 & 0.03 & 4.55 & 176 & 15269 & 0.85 \\
\hline
\end{tabular}

where DD is the mean raindrop diameter recorded by a disdrometer (Laser Precipitation Monitor from Thies Clima), and DT is the mean diameter estimated by the thermographic technique.

*Number of drops sampled "instantaneously" by technique in one pre-heated board; and **Number of drops sampled by disdrometer in one minute.

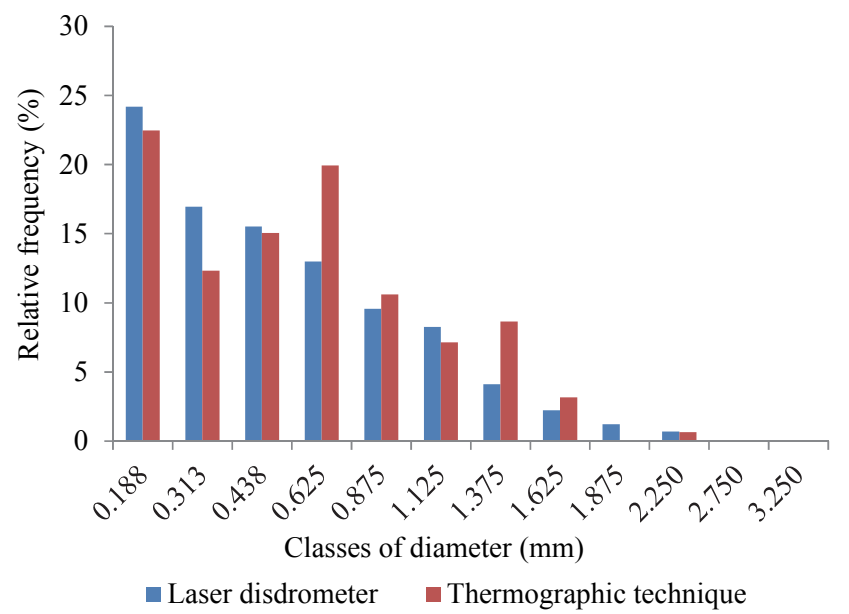

Fig. 9. Histogram of the combined sample of all data from the 9 individual samples presented in Figure 8. Values on the horizontal axis represent the middle of each diameter class.

for a number of drop diameter classes is shown in Figure 8, for the 9 samples collected from two rainfall events. We highlight again that whereas the thermographic data are for 9 different instants the disdrometer data are for 9 different minutes, which are paired in Figures 7 and 8.

As explained before, the Nash-Sutcliffe efficiency coefficient was used to compare the ability of the thermal approach to estimate the relative frequency of the drops' diameter classes, in comparison to the estimate provided by the disdrometer data. For the 9 samples, results are given in Table 1; the NSE coefficients are always positive and vary between 0.14 and 0.70 , but are above 0.6 for $40 \%$ of samples, indicating a good efficiency of the technique. The wide range of NSE values is not surprising because the samples are very small.
To overcome the small size of the samples, we have studied also a combined sample, created from the nine individual samples (i.e. data pool from several rain collections). Figure 9 shows that when comparing the histograms obtained from the thermographic and disdrometer data for the combined sample, results suggest a much better performance of the thermographic technique: we have obtained a Nash-Sutcliffe coefficient of 0.85 that is higher than observed before for the individual small samples. Thus, contrary to the individual samples, the results obtained for the combined sample are much closer to the laser disdrometer results. The reason is that the nine rainfall samples analysed with thermography can be considered instantaneous samples; in addition, their size is small. The observed rain fluctuations must be due both to statistical sampling errors (sampling fluctuations) and to real fine-scale physical variations (natural variability).

\section{CONCLUSION}

A simple technique based on infrared thermography and making use of relatively inexpensive equipment is described and explored in this study; this is a novel technique for estimating raindrop sizes, which belong to the class of time integrating approaches. Preliminary results obtained in this exploratory experiments show that this method is easy and fast to apply. The method has also revealed to be a promising approach with respect to its ability to provide a reliable insight on the raindrops' sizes.

This thermographic technique allowed us to estimate the mean drop diameter and the histograms of drops' diameter of natural rainfall. Such ability of the proposed technique was evaluated by comparing the thermographic results with laser disdrometer data. The difference between the mean drop diameters obtained using the disdrometer and the described thermographic technique was on average below $10 \%$ for the 9 samples explored in this study. The results obtained for the relative 
frequency of drops in different diameter class intervals also indicates good efficiency of the thermographic technique; however, as expected, results were worse for small samples, because small samples do not allow us to grasp the variability of the rain process.

The relatively easy handling of the necessary equipment and less time spent on analysis in comparison to other simplified techniques (e.g. paper blotter stains method, flour pellets method) make this procedure an interesting alternative. Although lacking the superior capability of laser disdrometers and optical raindrop spectrometers, it resolves the frequently encountered problem in low cost soil erosion studies of assessing rainfall drop sizes distributions. However, this first exploratory study must be complemented with more field work in different types of rainfall events with different conditions (e.g. wind); for example, problems might arise if this method is attempted when high winds or gusts prevail. Further research steps should lead to combining this technique with a method of sizing and counting automatically the samples' raindrops. Potential future applications of infrared thermography in hydrology should be envisioned and further explored.

Acknowledgements. The experimental work described in this study was carried out at the Laboratory of Hydraulics, Water Resources and Environment of the Department of Civil Engineering of the Faculty of Science and Technology, University of Coimbra (Portugal). This research was supported by the scholarship program for Special Visiting Researcher of the Brazilian scientific mobility program Science Without Borders, funded by $\mathrm{CNPq} / \mathrm{MCT}$, of the first author. The second author acknowledges CAPES, Brazil, for the Doctoral grant 11526/13-0.

\section{REFERENCES}

Atlas, D., Srivastava, R.C., Sekhon, R.S., 1973. Doppler radar characteristics of precipitation at vertical incidence. Rev. Geophys. Space Phys., 11, 1-35.

Bentley, A., 1904. Studies of Raindrops and Raindrop Phenomena. Monthly Weather Review, 32, 450-456.

Bradley, S.G., Stow, C.D., 1974. The measurement of charge and size of raindrops: Part I. The disdrometer. J. Appl. Meteorol., 13, 114-130.

Cardenas, M.B., Harvey, J.W., Packman, A.I., Scott, D.T., 2008. Ground-based thermography of fluvial systems at low and high discharge reveals potential complex thermal heterogeneity driven by flow variation and bioroughness. Hydrol. Process., 22, 7, 980-986.

Cataneo, R., Stout, G.E., 1968. Raindrop-size distributions in humid continental climates, and associated rainfall rate-radar reflectivity relationships. J. Appl. Meteorol., 7, 901-907.

Danielescu, S., MacQuarrie, K.T.B., Faux, R.N., 2009. The integration of thermal infrared imaging, discharge measurements and numerical simulation to quantify the relative contributions of freshwater inflows to small estuaries in Atlantic Canada. Hydrol. Process., 23, 20, 2847-2859.

de Lima, J.L.M.P., Abrantes, J.R.C.B., 2014a. Can infrared thermography be used to estimate soil surface microrelief and rill morphology? Catena, 113, 314-322.

de Lima, J.L.M.P., Abrantes, J.R.C.B., 2014b. Using a thermal tracer to estimate overland and rill flow velocities. Earth Surf. Process. Landforms, 39, 10, 1293-1300.

de Lima, J.L.M.P., Abrantes, J.R.C.B., Silva Jr, V.P., Montenegro, A.A.A., 2014. Prediction of skin surface soil permeability by infrared thermography: a soil flume experiment. Quantitative Infrared Thermogr. J., 11, 2, 161-169.

Eigel, J.D., Moore, I.D., 1983. A simplified technique for measuring raindrop size and distribution. Transactions of the ASABE - American Society of Agricultural and Biological Engineers, 26, 4, 1079-1084.

Hauser, D., Amayenc, P., Nutten, B., Waldteufel, P., 1984. A new optical instrument for simultaneous measurement of raindrop diameter and fall speed distribution. J. Atmos. Oceanic Technol., 1, 256-269.

Jarman, R.T., 1956. Stains produced by drops on filter paper. Royal Meteorological Society Quarterly J., 82, 252.

Jones, D.M.A., 1992. Raindrop spectra at the ground. J. Appl. Meteorol., 31, 1219-1225.

Joss, J., Waldvogel, A., 1969. Raindrop size distribution and sampling size errors. J. Atmos. Sci., 26, 566-569.

Knollenberg, R.G., 1970. The optical array: An alternative to scattering or extinction for airborne particle size determination. J. Appl. Meteorol., 9, 86-103.

Laws, J.O., Parsons, D.A., 1943. The relation of raindrop-size to intensity. Trans. Amer. Geophys. Union, 24, 452-460.

Magarvey, R.H., 1957. Stain Method of Drop-Size Determination. J. Meteorol., 14, 182-184.

Marshall, J.S., Langille, R.C., Palmer, W.M., 1947. Management of rainfall by radar. J. Meteorol., 4, 186-192.

Mejías, M., Ballesteros, B.J., Antón-Pacheco, C., Domínguez, J.A., Garcia-Orellana, J., Garcia-Solsona, E.G., Masqué, P., 2012. Methodological study of submarine groundwater discharge from a karstic aquifer in the Western Mediterranean Sea. J. Hydrol., 464-465, 27-40.

Nash, J.E., Sutcliffe, J.V., 1970. River flow forecasting through conceptual models, Part I-a discussion of principles. J. Hydrol., 10, 3, 282-290.

Pearson, J.E., Martin, G.E., 1957. An evaluation of raindrop sizing and counting techniques. Scientific Report No. 1, Illinois State Water Survey and the University of Illinois, Urbana, Illinois, USA, 116 p.

Pfister, L., McDonnell, J.J., Hissler, C., Hoffman, L., 2010. Ground-based thermal imagery as a simple, practical tool for mapping saturated area connectivity and dynamics. Hydrol. Process., 24, 21, 3123-3132.

Schuetz, T., Weiler, M., Lange, J., Stoelzle, M., 2012.Twodimensional assessment of solute transport in shallow waters with thermal imaging and heated water. Adv. Water Resour., 43, 67-75.

Sekhon R.S., Srivastava, R.C., 1971. Doppler radar observations of drop-size distributions in a thunderstorm. J. Atmos. Sci., 28, 983-994.

Thies, A., 2007. Instruction for Use 021341/08/07. Laser Precipitation Monitor 5.4110.xx.x00 V2.4x STD. 64.

Uijlenhoet, R., 1999. Parameterization of Rainfall Microstructure for Radar Meteorology and Hydrology. Doctoral thesis, Wageningen University, Wageningen, The Netherlands.

Wang, P.K., Pruppacher, H.R., 1977. Acceleration to terminal velocity of cloud and raindrops. J. Appl. Meteorol., 16, 275280.

Wang, T., Earnshaw K.B., Lawrence, R.S., 1979. Path-averaged measurements of rain rate and raindrop size distribution using a fast-response optical sensor. J. Appl. Meteorol., 18, 654-660.

Received 11 November 2014 Accepted 2 March 2015

Note: Colour version of Figures can be found in the web version of this article. 